\title{
PROPERTIES OF STRAIN-GAUGE LOAD CELLS APPLIED FOR STATOR REACTION MEASUREMENT
}

This contribution deals with experience with the measurement of the stator reaction of the dynamometer using load cells. Originally, the stator reaction had been measured using a balance mechanism. Within the framework of the author's research, it was necessary to improve the accuracy of torque measurement of the dynamometer. To accomplish this requirement, the old balance mechanism was replaced by a straingange load cell. Two various types of the load cells were applied in order to arrange the measuring range to the expecting range of values of the torque. During the calibration, hysteresis in voltage output of the both applied load cells was observed. The maximal value of the hysteresis was about $0.5 \%$ of the measured range of both of the load cells. Moreover, a certain temporary-plasticity of both of the load cells occurred.

Keywords: Strain-gauge, load cell, hysteresis, dynamometer, torque.

\section{Introduction}

An older type of eddy current dynamometer [1] was applied in laboratory for torque measurement. Originally, torque of the engine, as a stator reaction, was measured using a balance mechanism A precise measurement of the torque of the internal combustion engine (ICE) is very important in the author's research especially in case of the low engine load. Moreover, precise measurement of the torque enables the measurement with a constant value of the tested engine torque $(\mathrm{Mt})$

As the increase of the measurement accuracy had been required, the balance mechanism was replaced by a commercial strain-gauge load cell, see Fig. 1. A measuring amplifier [2] was used both as a source for Wheatstone's bridge excitation voltage and as an output signal conditioning. Load cell output signal was converted by the measuring amplifier to the unified voltage output signal $( \pm 10 \mathrm{~V})$. This voltage output depends on the load (measured torque) and can be evaluated either by the voltmeter or by the appropriate inputs of the Data AcQuisition System (DAQ).

Note that all the measured data are acquired during the measurement using a DAQ system that was developed and commonly used in the author's laboratory as a standard part of the experimental equipment. More information on the test bed has been presented in [1] and [3].

Moreover, to protect the applied load cell against the excessive values of load, a protection (Force Stop) was designed [4] and installed near the load cell, as illustrated in Fig. 1. The force stop was designed in such a way that the activating of the force stop is adjustable. More about the load cell protection will be described bellow.

The next paragraph will describe the performed calibration measurements of both of the load cells and their detected properties.

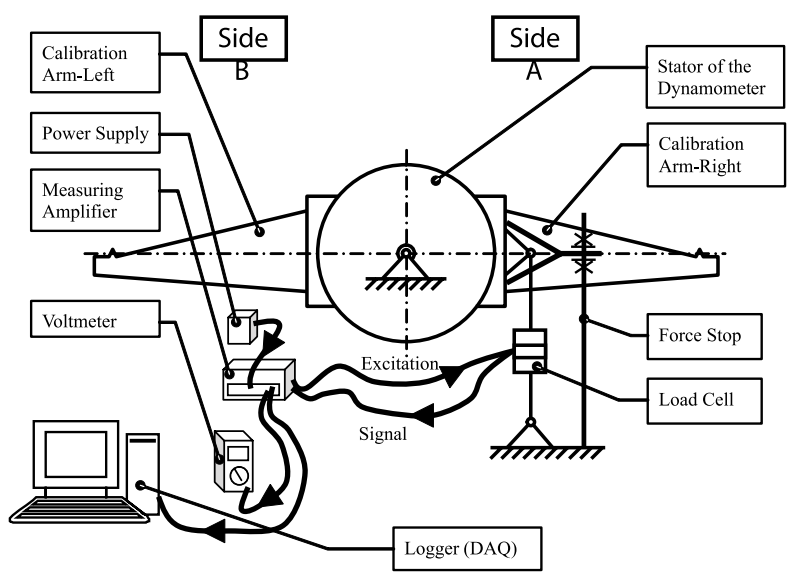

Fig. 1 Scheme of the measurement of the stator reaction using the load cell.

\section{Performed Calibration Measurements}

Within the framework of the author's research a question of enhanced accuracy torque (Mt) measurement was solved. It con-

\footnotetext{
* Lubomir Miklanek

Josef Bozek Research Center, Faculty of Mechanical Engineering, Czech Technical University in Prague, Czech Republic,

E-mail: lubomir.miklanek@fs.cvut.cz
} 
cerns the test bed with the S $781 \mathrm{NG}$ engine (it is four-cylinder internal combustion, spark-ignition engine made by manufacturer Škoda with max. value of $\mathrm{Mt}=90 \mathrm{Nm}$ ). To solve this task, the load cell (further marked as load cell-1) with these parameters was applied: (Max. loading (Rated load): $490 \mathrm{~N}$; Gauge-factor: $1.8553 \mathrm{mV} / \mathrm{V}$; Input impedance: $415 \Omega$; Material: anodized aluminum; 6-wire technique with two sensor lines), [5].

The properties of the applied load cell were detected by the calibration measurements. The calibration of the load cell was performed for both sides A and B (both torque direction), see Fig. 1. The measured patterns are presented in Fig. 2 and Fig. 3. Used marking in Figures: Mtcalibration is calibration torque; $M t$ is measured torque using the load cell.

There was also a requirement to increase the accuracy of higher torque measurement of other engine. The engine should be a mass-produced four-cylinder 1.9-liter light-duty diesel engine, turbocharged with the air inter-cooler. Its nominal power was of $66 \mathrm{~kW}$ at $4000 \mathrm{rpm}$ and peak torque of $202 \mathrm{~N} . \mathrm{m}$ at $1900 \mathrm{rpm}$. In order to solve this task, the load cell (further marked as load cell-2) with these parameters was applied: (Max. loading (Rated load): 1962 $\mathrm{N}$; Gauge-factor: $2.0011 \mathrm{mV} / \mathrm{V}$; Input impedance: $395 \Omega$; Material: stainless steel; 6-wire technique with two sensor lines), [6].

The properties of this load cell-2 were detected by the calibration as in case of the load cell1. The calibration was performed for both sides A and B (both torque direction) as well. The measured patterns are presented in Fig. 4 and Fig. 5. The marking used in these Figures is the same as in Figs. 2 and 3.

\subsection{Calibration of the Load Cell-1 on Side B}

The calibration began on side B (tension). The load cell-1 was under no loading a few hours before the calibration process.

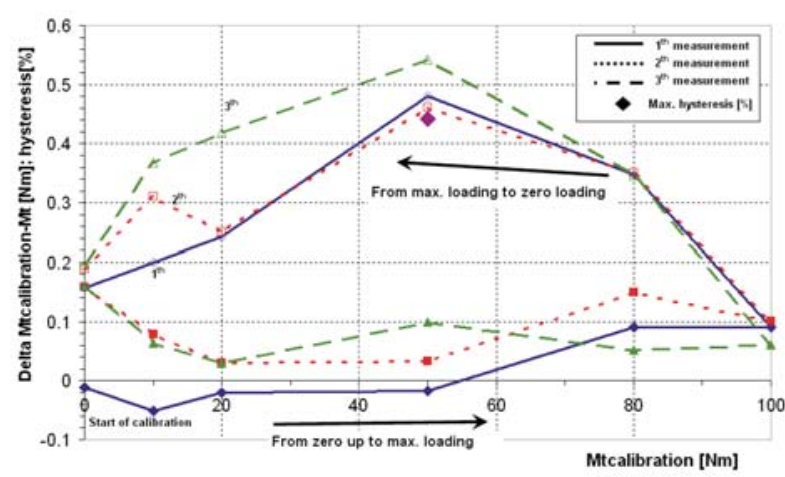

Fig. 2 Measured patterns during the calibration of the applied load cell-1 on side B

The calibration was performed from the zero loading up to the maximal loading and back to the zero loading. This calibration process was repeated three times consecutively, see Fig. 2. As it is seen in Fig. 2, hysteresis occurred between both the increasing and decreasing loading. Its maximal value was about $0.45 \%$ of the measured range during the calibration.

Moreover, certain temporary-plasticity occurred. The term "temporary-plasticity" will be explained in the paragraph below. This observed temporary-plasticity caused a certain offset in the measuring amplifier voltage output especially at the zero loading of the load cell, as it is seen in Fig. 2. Its maximal value was about $0.17 \%$ of the measured range at the zero loading.

\subsection{Calibration of the Load Cell-1 on Side A}

After the calibration on side B, the calibration on side A (compression) was performed. The measured patterns are presented in Fig. 3. As in the previous case, all three calibration measurements were performed consecutively. The hysteresis with its maximal value of about $0.66 \%$ was occurred.

However, the observed temporary-plasticity from the previous calibration on side B at the zero loading was changed to the direction of load, see Fig. 3. As it can be seen from Fig. 3, the change of temporary-plasticity direction was made just after the first calibration measurement, which is very interesting. It means the maximal value of the temporary-plasticity was doubled (about $2 \mathrm{x}$ $0.17 \%$ of the measured range) at the end of the first calibration measurement.

Observed temporary-plasticity was not changed significantly during the second and third calibration measurement and the value was about $0.17 \%$ at the zero loading, see Fig. 3 .

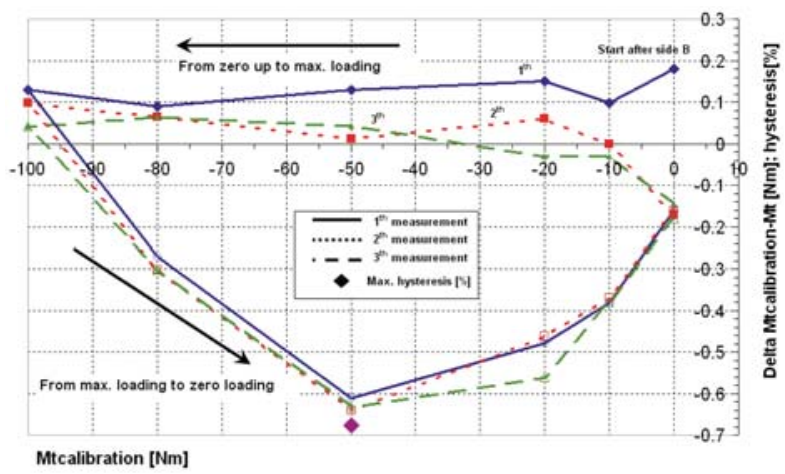

Fig. 3 Measured patterns during the calibration of the applied load cell-1 on side A

\subsection{Calibration of the Load Cell-2 on the Side B}

As mentioned before, for the higher value of the torque measurement, the load-cell-2 was applied. The calibration began on side B (tension). On the contrary to the calibration of the load 
cell-1, the load cell-2 was under loading a few minutes before the calibration process.

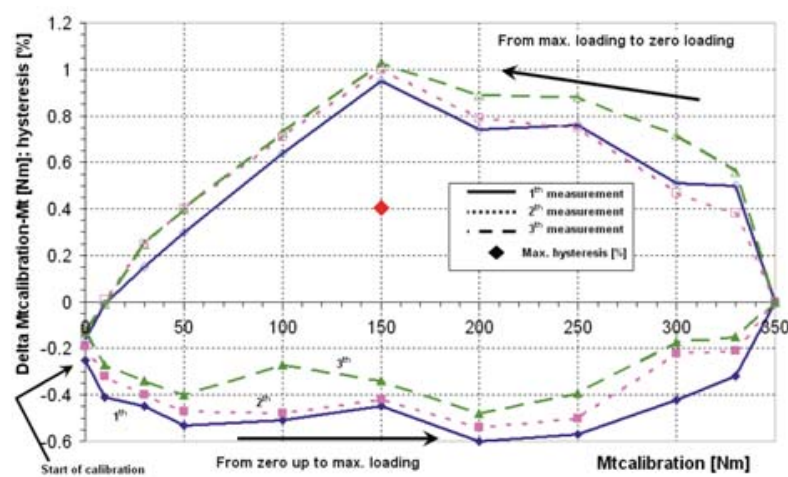

Fig. 4 Measured patterns during the calibration of the applied load cell2 on side $B$

As previously, the calibration was performed from the zero loading up to the maximal loading (tension) and back to the zero loading. This calibration process was repeated three times consecutively, see Fig. 4. As it is seen in Fig. 4, hysteresis occurred between both the increasing and decreasing loading. Its maximal value was below $0.5 \%$ ( $0.4 \%)$ of the measured range during the calibration.

Probably due to the fact that the load cell-2 was loaded before the calibration in the direction of calibration loading, the temporary-plasticity did not occur, see Fig.4.

\subsection{Calibration of the Load Cell-2 on Side A}

After the calibration on side B, the calibration on side A (compression) was performed. The measured patterns are presented in Fig. 5. As in the previous case on side B, all three calibration measurements were performed consecutively. The hysteresis with its maximal value of about $0.44 \%$ (below $0.5 \%$ again) occurred between both the increasing and decreasing loading.

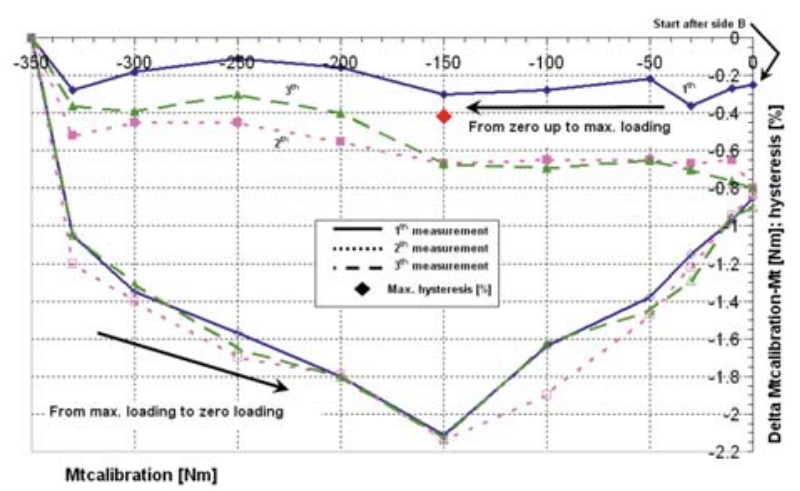

Fig. 5 Measured patterns during the calibration of the applied load cell-2 on side $A$
Moreover, the temporary-plasticity at the zero loading occurred as can be seen in Fig. 5. Observed temporary-plasticity at the zero loading was changed to the direction of load. The change of temporary-plasticity direction was made just after the first calibration measurement, similarly to the load cell-1 in Fig. 3.

Based on the patterns in Fig. 3 (load cell-1) the temporaryplasticity is at the end of the first calibration measurement two times more. It means the value on the Y-axis (Delta Mtcalibration$\mathrm{Mt})$ at the zero loading of the load cell- 2 should be about " $-0.5 \mathrm{Nm}$ " without any influence of the plasticity. Upon this presumption, the maximal value of the temporary-plasticity should be about $0.086 \%$ of the measured range. It is about two times less than in case of the load cell-1.

In Figs. 3 and 5 it can be seen that the properties of both load cells were quasi turned over by a change of the direction of the load. After finishing the first calibration, the properties of the load cells change only negligibly, which is interesting.

\section{Temporary-plasticity elimination}

As mentioned before, certain plasticity was observed after the calibration of both load cells, see Figs. 2, 3 and 5. Nevertheless, it was observed that the mentioned plasticity (on sides A and B) disappeared by itself after a few hours of the zero loading of the load cell under constant temperature conditions. Time record of the partial elimination of plasticity (about $66 \%$ after $4.5 \mathrm{~h}$ ) is shown in Fig. 6. Overall elimination of plasticity takes about 7 to 8 hours.

So-called Shape Memory Alloys (SMA) have similar properties (return to the original shape after being deformed), [7], [8]. These alloys allow a so-called pseudo-plasticity phenomenon. It means that alloy can be deformed by mechanical stress under normal temperature conditions. After finishing the mechanical stress, the deformation of alloy is fixed. Nevertheless, the alloy returns to the original shape (before the deformation) by heating the alloy on the appropriate temperature (about $400-500{ }^{\circ} \mathrm{C}$ ).

However, the measured properties of the load cell, shown in Fig. 6 (elimination of plasticity under almost constant temperature

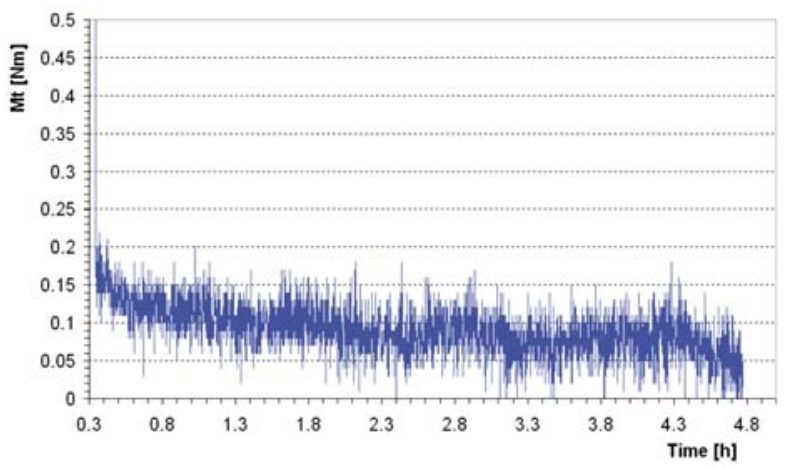

Fig. 6. Time-record of the partial elimination of temporary-plasticity by itself after a few hours under zero loading. 
conditions after a few hours) seem not to be properties like pseudoplasticity.

Based on the above described fact and assumption that the material of the load cell is not SMA, the author gives a name to this phenomenon: Temporary-plasticity. Please note, the author is no expert in metallurgy.

\section{Load Cell Protection}

Protection of the applied load cell is possible using a purposedesigned force stop, see Fig. 1. The design of the force stop makes an adjustment of its activation possible. When the loading of the tension-compression load cell is less than the preset value, the force stop is not active. However, when the loading of the load cell is larger than the preset value, the force stop is active. Once the force stop is activating, the load is split into both the load cell and the force stop. This splitting causes the change in measured patterns of loading of an applied load cell, see Fig. 7. In this Figure, the measured patterns of the load cell- 1 are presented before and after the force stop activating.

It is seen that after the force stop activating, the loading of the load cell increases only slightly compared to the loading increasing without the force stop. Note, the maximum safe static overload of this type of load cell is about $150 \%$ of the rated load. The force stop should be activated at latest on the rated load.

The patterns of load cell- 2 before and after the force stop activating are very similar.

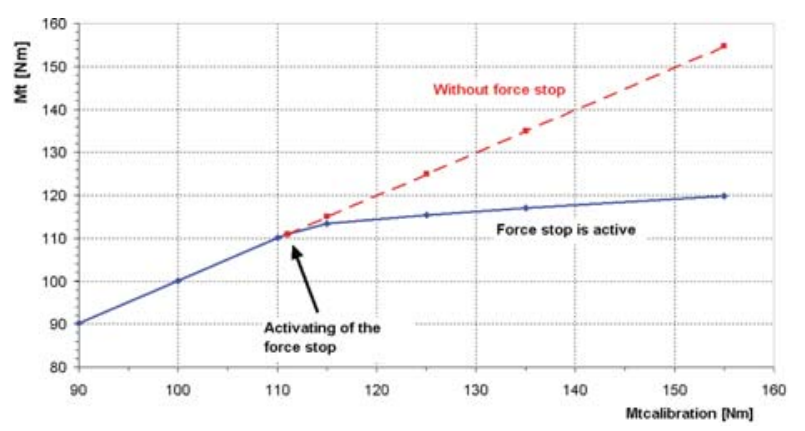

Fig. 7 Measured patterns of loading of the load cell-1 before and after force stop activating

\section{Conclusion}

Properties of the applied load cell (Max. loading (Rated load): $490 \mathrm{~N}$; Gauge-factor: $1.8553 \mathrm{mV} / \mathrm{V}$; Input impedance: $415 \Omega$; Material: anodized aluminum; 6-wire technique with two sensor lines) was observed during the calibration in both directions of stress - tensile stress (side B) and compression stress (side A). During the calibration, the hysteresis in voltage output signal was observed (about $0.45 \%$ of the measured range in direction of tensile stress and about $0.66 \%$ in direction of compression stress). Moreover, certain temporary-plasticity of the load cell (about $0.17 \%$ of the measured range) occurred. This temporary-plasticity caused the small offset in output voltage especially in the zero loading.

Moreover, the other load cell (Max. loading (Rated load): 1962 N; Gauge-factor: $2.0011 \mathrm{mV} / \mathrm{V}$; Material: stainless steel; 6wire technique with two sensor lines) was calibrated for another engine torque measurement in both directions of stress - tensile stress (side B) and compression stress (side A).

Surprisingly, observed hysteresis in voltage output signal of the load cell- 2 was about $0.4 \%$ of the measured range as well, although the load cell-2 was made from different material as the load cell-1.

However, the observed temporary-plasticity of the load cell-2 was almost on the half value compared to the load cell-1. It must be noted that the rated load of the load cell-2 is four-times larger than the rated load of the load cell-1.

Based on the measured patterns in Figs. 3 and 5, the properties of both load cells are changed by a change of direction of the load. Moreover, the properties of the load cells are almost constant after the first loading (from the zero loading up to the maximal loading and back to the zero loading) in case of a change in the direction of the load.

In the author's opinion, these observed properties of the applied load cells have no significant effect on the required accuracy of measurements compared to the measured ranges.

\section{Acknowledgement}

This contribution has been elaborated with the support of the project 1M6840770002 - Josef Božek Research Center of Engine and Automotive Technology. The author gratefully acknowledges this support.

\section{References}

[1] MIKLANEK, L. Utilization of Automation Test Process in Transient Engine Operating State. Mecca, 3/2003, vol. I, p. 42-48, ISSN 1214-0821.

[2] HOTTINGER BALDWIN MESSTECHNIK GMBH: Clip Electronic. Operating Manual, 2008.

[3] TAKATS, M.: In-cylinder Pressure Recording and Data Acquisition System. Mecca, 4/2003, vol. 1, p. 29-35, ISSN 1214-0821, 2003.

[4] MIKLANEK, L.: Strain-gauge Load Cell. Patent application, No. 2007-433, Industrial Property Office, Prague, 2007.

[5] TEDEA-HUNTLEIGH ELECTRONICS. CO.LTD: Load Cell Test Data Sheet-Model 614, 50kg. 2008.

[6] TEDEA-HUNTLEIGH ELECTRONICS. CO.LTD: Load Cell Test Data Sheet-Model 616, 200kg. 2007.

[7] http://en.wikipedia.org/wiki/Shape_memory_alloy

[8] http://cs.wikipedia.org/wiki/Slitiny_s_tvarovou_pam\%C4\%9Bt\%C3\%AD. 